\title{
PELATIHAN PENGGUNAAN PERALATAN LABORATORIUM FISIKA MATERIAL DAN RISET BAGI GURU-GURU FISIKA SMA SE KOTA MANADO
}

\author{
Donny R. Wenas \\ Program Studi Fisika, Fakultas Matematika dan Ilmu Pengetahuan Alam, \\ Universitas Negeri Manado (UNIMA) \\ donny wenas@unima.ac.id
}

\begin{abstract}
Abstrak
Kemampuan melaksanakan kegiatan praktikum/demonstrasi dan mengembangkan materi pembelajaran berbasis laboratorium adalah salah satu kompetensi guru fisika. Peningkatan kemampuan tersebut akan meningkatkan daya saing lulusan siswa. Tujuan pelaksanaan kegiatan pengabdian pada masyarakat ini adalah: 1) memperkenalkan pengetahuan tentang laboratorium Fisika material dan Riset bagi guru Fisika SMA se kota Manado; 2) memberikan pelatihan keterampilan penggunaan peralatan laboratorium Fisika material dan riset bagi guru Fisika SMA se kota Manado; 3) menjelaskan manfaat karakterisasi peralatan laboratorium Fisika Material dan Riset bagi guru Fisika SMA se kota Manado; dan 4) menjalin kerja sama antara dunia kerja yaitu Sekolah dengan Perguruan Tinggi (UNIMA) agar tercipta keserasian tentang kebutuhan Sumber Daya Manusia dilapangan dan kurikulum yang diterapkan khususnya pada Program Studi Fisika FMIPA UNIMA. Metode yang dilakukan adalah ceramah, demonstrasi, peragaan, diskusi dan evaluasi. Kegiatan ini akan menghasilkan produk berupa buku panduan bagaimana dan apa yang harus dilakukan dalam mengoperasikan peralatan laboratorium fisika material dan riset. Buku panduan akan dirancang semenarik mungkin disertai gambar dan keterangan serta langkah-langkah dalam mengoperasikan alat laboratorium. Disamping buku panduan, akan dibuat juga buku ajar tentang konsep dan teori terkait dengan peralatan laboratorium fisika material dan riset serta artikel ilmiah. Berdasarkan kegiatan yang dilaksanakan, maka diperoleh hasil sebagai berikut: 1) para peserta (Guru fisika SMA) mengenal pengetahuan tentang spektroskopi UV-Vis (Ultra Violet Visible); 2) memahami pengetahuan tentang spektroskopi FTIR (Fourier Transform Infra red); 3) mengenal pengetahuan tentang SEM-EDX (Scanning Electron Microscopic-Energy Dispersive X-Ray Spectrometric); dan 4) mampu mengoperasikan alat spektrometer UVVis, FTIR, dan SEM-EDX.
\end{abstract}

Kata Kunci: Laboratorium, spektrokopi, UV-Vis, FTIR, SEM-EDX..

\section{PENDAHULUAN}

Kemampuan melaksanakan kegiatan praktikum/demonstrasi dan mengembangkan materi pembelajaran berbasis laboratorium adalah salah satu kompetensi guru fisika, peningkatan kemampuan tersebut akan meningkatkan daya saing lulusan siswa. Penyelenggaraan kegiatan laboratorium dan hasilnya yang tidak maksimal, ditandai antara lain: tidak semua topik kegiatan praktek laboratorium terlaksana secara sinkron dengan materi pembelajaran, rataan nilai praktikum yang rendah dan lain-lain.

Pengamatan yang dilakukan setelah beberapa kali berkunjung di SMA yang berada di Sulawesi utara khususnya Manado, Minahasa dan Bitung, maka faktafakta hasil evaluasi menunjukkan bahwa penguasaan mata pelajaran fisika rendah, 
oleh siswa pelajaran fisika dipandang hanya teori saja tanpa demonstrasi/praktikum, dimana akar permasalahannya terletak pada sistem pembelajaran yang diterapkan selama ini hanya teori saja. Dengan kata lain jarang diterapkan model pembelajaran yang memungkinkan siswa langsung dapat mengamati gejala fisis yang terjadi lewat demonstrasi atau praktikum. Hal ini disebabkan karena belum tersedianya peralatan laboratorium untuk demonstrasi/praktikum yang memadai. Mendesain dan membuat alat demonstrasi Fisika adalah sangat perlu untuk memenuhi kebutuhan tersebut, dan baru pada saat ini mendesain, membuat dan menggunakan alat laboratorium fisika akan diterapkan.

Berdasarkan analisis situasi yang diuraikan di atas, maka jelaslah bahwa fakta atau kenyataan yang dihadapi oleh para guru fisika di SMA khususnya yang melaksanakan tugas di Kota Manado adalah rendahnya penguasaan penggunaan peralatan laboratorium fisika. Berdasarkan kenyataan itulah maka yang menjadi permasalahan adalah: Bagaimana meningkatkan penguasaan peralatan laboratorium fisika material dan riset bagi guru-guru fisika di SMA?

Tujuan pelaksanaan kegiatan pengabdian pada masyarakat ini adalah: 1) memperkenalkan pengetahuan tentang laboratorium Fisika material dan Riset bagi guru Fisika SMA se kota Manado; 2) memberikan pelatihan keterampilan penggunaan peralatan laboratorium Fisika material dan riset bagi guru Fisika SMA se Kota Manado; 3) menjelaskan manfaat karakterisasi peralatan laboratorium Fisika Material dan Riset bagi guru Fisika SMA se Kota Manado; dan 4) menjalin kerja sama antara dunia kerja yaitu Sekolah dengan Perguruan Tinggi (UNIMA) agar tercipta keserasian tentang kebutuhan Sumber Daya Manusia di lapangan dan kurikulum yang diterapkan khususnya pada Program Studi Fisika FMIPA UNIMA.

Manfaat kegiatan pengabdian pada masyarakat ini: 1) adanya pengenalan konsep fisis yang dapat dipahami lewat pelatihan/ bimbingan guru Fisika SMA dalam mengoperasikan peralatan laboratorium Fisika material dan riset sehingga guru bisa menerapkan proses pembelajaran berbasis laboratorium mengakibatkan siswa lebih mudah untuk memahami konsep fisis secara lebih baik, pengalaman guru dalam melakukan analisis kasus fisis lewat pelatihan laboratorium fisika material dan riset membuat mereka tidak mudah melupakan konsep yang sudah dipahami dan memiliki wawasan dalam riset fisika serta untuk penulisan artikel ilmiah, pola kegiatan pelatihan guru fisika dalam mengoperasikan peralatan laboratorium fisika material dan riset ini dapat menjadi acuan untuk pengembangan pola pada bidang studi lain yang menggunakan laboratorium, mendorong peningkatan efisiensi, terutama dalam hal pemanfaatan secara optimal sarana/peralatan laboratori- 
um yang telah tersedia, menghasilkan suatu hubungan kerjasama yang baik antara dosen dan guru serta siswa untuk kemitraan dalam hal pembelajaran fisika di sekolah, dan memotivasi dosen untuk melakukan pengkajian agar menghasilkan model pembelajaran fisika yang bermutu bagi sekolah.

\section{TINJAUAN PUSTAKA}

Spektroskopi adalah studi mengenai antaraksi antara energi cahaya dan senyawa organik yang dikenal dengan metoda fisikokimia (physicochemical methods). Absorpsi energi elektromagnetik menimbulkan perubahan molekular pada senyawa organik tersebut. Warna - warna yang terlihat dan fakta bahwa orang lain bisa melihat warna - warna tersebut adalah akibat absorpsi energi gelombang elektromagnetik oleh senyawa organik atau anorganik. Penangkapan energi matahari oleh tumbuhan dalam proses fotosintesis adalah salah satu aspek lain dari antaraksi senyawa organik dengan energi cahaya.

Perhatian utama bagi ahli fisika, kimia organik adalah fakta bahwa panjang gelombang bila senyawa organik menyerap cahaya, bergantung pada struktur senyawa organik tersebut. Setiap senyawa organik akan menyerap energi gelombang elektromagnetik yang berbeda, oleh karena itu teknik - teknik spektroskopi dapat digunakan untuk menentukan struktur senyawa organik yang tak diketahui atau untuk mempelajari karakteristik ikatan dari senyawa organik yang diketahui.

Jika radiasi ringan melalui sampel senyawa organik, selanjutnya beberapa panjang gelombang diserap sementara radiasi lainnya tidak berpengaruh. Suatu molekul hanya dapat menyerap radiasi dari frekuensi tertentu, jika terdapat diantara molekul besarnya transisi energi adalah, $\Delta E$ $=h v$. Jika cahaya dengan frekuensi yang sesuai mengenai suatu molekul pada keadaan dasar $\psi_{0}$, diserap dan mengangkat molekul ke keadaan yang tereksitasi $\psi_{i}$. Secara emisi spontan atau secara emisi stimulant, menyebabkan sinar cahaya kembali ke keadaan dasar. Kata "dapat" mengungkapkan kemungkinan transisi dari dua proses radiasi, serapan dan emisi.

Ditemukan bahwa jika radiasi ringan melalui senyawa organik, selanjutnya elektron dari senyawa tersebut tereksitasi, demikian halnya dengan energi vibrasi dan rotasi. Selanjutnya, beberapa panjang gelombang cahaya yang diserap oleh molekul tertentu akan menyebabkan perubahan tingkat energi transisi, vibrasi atau rotasi. Panjang gelombang yang diserap diukur dengan pertolongan spektrometer. Jika diplot perubahan absorpsi terhadap panjang gelombang, kita akan mendapatkan pita serapan tertentu yang sangat karakteristik untuk suatu senyawa, dan teknik yang memberikan cara terbaik untuk menentukan struktur molekul, ringkasan teknik - teknik 
spektroskopi dan perubahan yang terjadi pada suatu molekul.

Radiasi elektromagnetik adalah energi yang dipancarkan menembus ruang dalam bentuk gelombang - gelombang. Tiap tipe radiasi elektromagnetik (gelombang radio, ultra violet, tampak (visible), dan lain - lain) dicirikan oleh panjang gelombang (wavelength, $\lambda$ ) yaitu jarak antara puncak panjang gelombang yang satu ke puncak panjang gelombang berikutnya panjang gelombang cahaya tampak berkisar antara 400 - $750 \mathrm{~nm}(1 \mathrm{~nm}=10-9 \mathrm{~m})$, namun daerah tampak ini hanyalah bagian sangat kecil dari keseluruhan spektrum elektromagnetik. Panjang gelombang yang lebih pendek dari pada panjang gelombang cahaya tampak adalah daerah ultraviolet, sedangkan yang lebih panjang adalah daerah inframerah. Disamping dicirikan oleh panjang gelombang, radiasi dapat dicirikan oleh frekuensinya (frequency), yang didefiniskan sebagai banyaknya daur (lingkar) lengkap tiap detik (cps, cycle per second) yang juga disebut $\mathrm{Hertz}(\mathrm{Hz})$. Radiasi dengan frekuensi lebih tinggi mengandung lebih banyak gelombang perdetik, oleh karena itu panjang gelombangnya haruslah lebih pendek (panjang gelombang dan frekuensi berbanding terbalik). Hubungan ini dapat diungkapkan secara matematik sebagai berikut:

$$
v=\frac{c}{\lambda}
$$

dengan:

$$
\begin{aligned}
& v=\text { frekuensi }(\mathrm{Hz}) \text {; } \\
& c=3 \times 10^{10} \mathrm{~cm} / \text { detik (laju rambat } \\
& \text { cahaya); dan } \\
& \lambda=\text { panjang gelombang }(\mathrm{cm}) \text {. }
\end{aligned}
$$
kuensi dinyatakan dalam bilangan gelombang (wavenumbers); banyaknya daur per sentimeter. Satuan bilangan gelombang adalah persentimeter $\left(1 / \mathrm{cm}\right.$ atau $\left.\mathrm{cm}^{-1}\right)$. Satuan yang digunakan untuk panjang gelombang dalam spektroskopi inframerah adalah mikrometer $(\mu \mathrm{m})$. Bilangan gelombang $\left(\mathrm{cm}^{-1}\right)=\frac{1}{\lambda(\mathrm{cm})}=\frac{1}{\lambda(\mu \mathrm{m})} \times 10^{4}$.

Radiasi elektromagnetik dipancarkan dalam bentuk paket - paket energi yang menyerupai partikel yang disebut foton atau kuantum. Energi suatu foton berbanding terbalik dengan panjang gelombangnya:

$$
E=h \frac{c}{\lambda}
$$

dengan $h=$ Tetapan Planck $\left(6,63 \times 10^{-27}\right.$ erg detik).

Radiasi dengan panjang gelombang lebih pendek mempunyai energi yang lebih tinggi, oleh karena itu sebuah foton cahaya ultraviolet berenergi lebih tinggi dari pada sebuah foton cahaya tampak dan jauh lebih tinggi daripada sebuah foton gelombang radio.

Molekul menyerap hanya radiasi elektromagnetik dengan panjang gelombang yang khusus (spesifik untuk molekul itu). 
Absorpsi cahaya ultraviolet (radiasi berenergi tinggi) mengakibatkan pindahnya sebuah elektron ke orbital dengan energi yang lebih tinggi. Radiasi inframerah tidak cukup mengandung energi untuk mempromosikan elektron semacam itu; absorpsi radiasi inframerah hanya mengakibatkan membesarnya amplitudo getaran atom atom yang terikat satu sama lain. Bila suatu contoh senyawa menyerap foton - foton radiasi, maka banyaknya foton yang berhasil melewati senyawa organik itu akan lebih rendah daripada yang mula - mula memasuki senyawa organik. Absorpsi ini akan diamati sebagai menurunnya intensitas (atau kuantitas) radiasi. Perubahan intensitas inilah yang digunakan sebagai suatu pengukuran dalam spektroskopi.

\section{METODE PELAKSANAAN}

Metode atau pola pemecahan yang dilakukan dalam kegiatan ini adalah menggunakan beberapa tahap yang dapat dijelaskan sebagai berikut:

1. Pertama untuk memperoleh data tentang penggunaan peralatan laboratorium fisika di SMA, dilakukan survei ke sekolah dan mewawancarai Guru Fisika SMA di Kota Manado. Hasil survei dilanjutkan dengan analisis penyusunan materi penggunaan peralatan laboratorium fisika bagi guru-guru SMA di Kota Manado.

2. Tahap kedua adalah memberikan pelatihan penggunaan peralatan laboratorium fisika material dan riset bagi guru-guru fisika SMA di Kota Manado. Guru-guru Fisika SMA mendapatkan pelatihan yang diawali dengan pengetahuan tentang peralatan laboratorium fisika material dan riset yaitu: UV-Vis, FTIR, SEM-EDX.

3. Kemudian dilanjutkan dengan demonstrasi dan pelatihan pengoperasian alat. Urutan secara rinci adalah sebagai berikut:
a. memperkenalkan pengetahuan tentang spektroskopi UV-Vis (Ultra Violet Visible);
b. memperkenalkan pengetahuan tentang spektroskopi FTIR (Fourier Transform Infra Red);
c. memperkenalkan pengetahuan ten- tang SEM-EDX (Scanning Electron Microscopic-Energy Dispersive Xray Spectrometric);
d. pelatihan pengoperasian alat UV-Vis, FTIR, dan SEM-EDX; dan
e. evaluasi.

\section{HASIL DAN PEMBAHASAN}

Berdasarkan kegiatan yang dilaksanakan, maka dapat diketahui hasil kegiatan sebagai berikut:

1. Para peserta (Guru fisika SMA) mengenal pengetahuan tentang spektroskopi UV-Vis (Ultra Violet Visible);

2. Para peserta (Guru fisika SMA) memahami pengetahuan tentang spektroskopi FTIR (Fourier Transform Infra Red); 
Jurnal ABDIMAS, Vol. 11, No. 2, Agustus 2018

ISSN: 1979-0953 | e-ISSN: 2598-6066
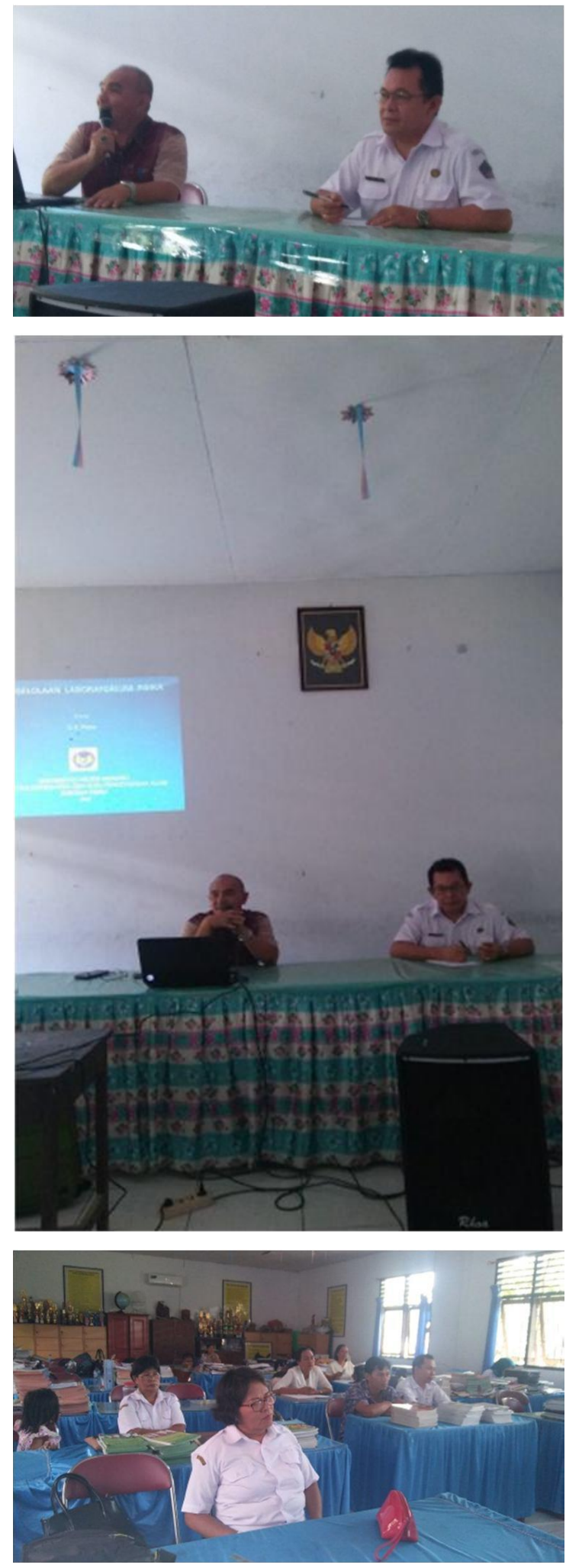

Gambar 1. Dokumentasi pelaksanaan kegiatan.

3. Para peserta (Guru fisika SMA) mengenal pengetahuan tentang SEM-EDX
(Scanning Electron Microscopic-Energy Dispersive Xray Spectrometric); dan

4. Para peserta (Guru fisika SMA) mampu mengoperasikan alat tentang UV-Vis, FTIR, dan SEM-EDX.

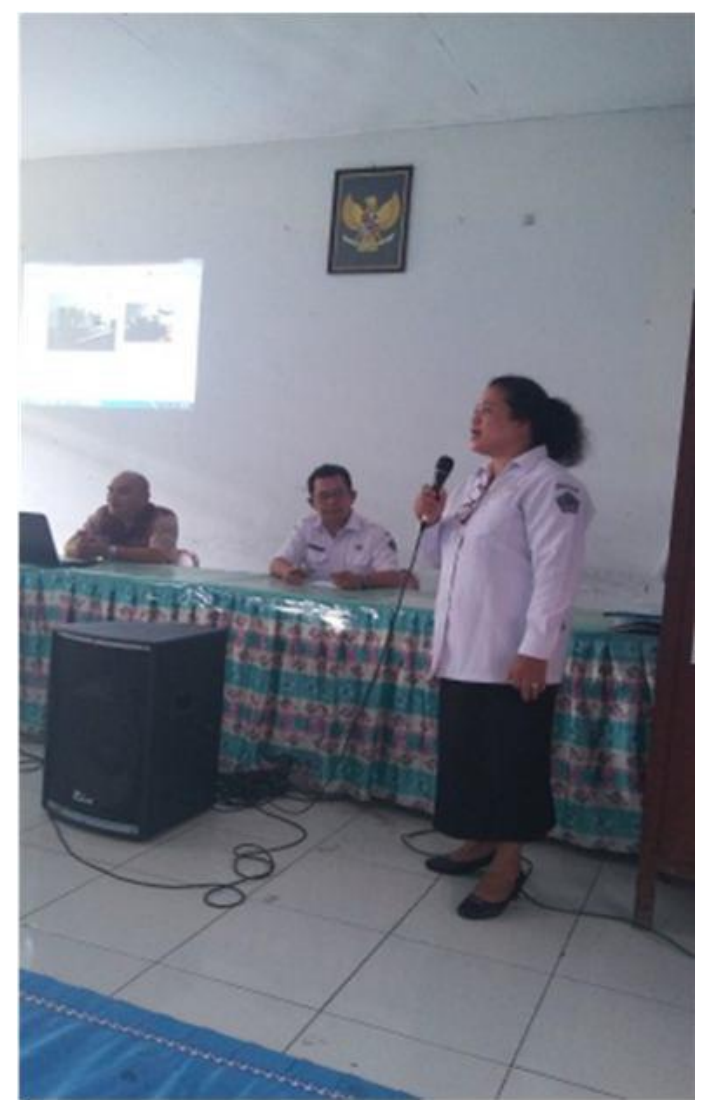

Gambar 2. Dokumentasi lanjutan pelaksanaan kegiatan.

\section{KESIMPULAN}

Melalui kegiatan pengabdian pada masyarakat ini, dapat disimpulkan bahwa para peserta pelatihan (Guru-guru Fisika SMA di kota Manado) dapat mengenal, memahami dan mampu mengoperasikan peralatan spektroskopi UV-Vis, FTIR, dan SEM-EDX. 


\section{KEPUSTAKAAN}

Demarco,P.V, et al, (2000), J. Am.Chem. Soc, $92,5737$.

Goering, H.L, et al, (2001), J. Am. Chem. Soc, 93, 5913.

Jarpars.M, (2003), Natural. Products. Report, 16, 241-248.
Pavia,D.L., Lampman, G.M., Kriz, G.S., (2001), "Introduction to Spectroscopy" third edition, Thomson Learning.

Silverstein, R.M., Webster, F.X., Kiemle, D.J., (2005), "Spectrometric Identification of Organic Compounds" seventh edition, John Wiley and Sons.

SOP Spektroskopi UV-Vis dan FTIR dari Perkin Elmer. 
Jurnal ABDIMAS, Vol. 11, No. 2, Agustus 2018

ISSN: 1979-0953 | e-ISSN: 2598-6066 